\title{
RECURSOS FORESTALES, PROYECTOS DE EXTRACCIÓN Y ASIENTOS DE MADERAS EN LA NUEVA ESPAÑA DURANTE EL SIGLO XVIII
}

\author{
RAFAL REICHERT \\ Instituto de Estudios Ibéricos e Iberoamericanos-Universidad de Varsovia, Polonia
}

\begin{abstract}
RESUMEN. El objetivo de este artículo es estudiar los recursos forestales novohispanos y su aprovechamiento para el desarrollo de la construcción naval española en el siglo XVIII. Un aspecto poco conocido por las historiografías española y latinoamericana, que, sin embargo, es importante a la hora de conocer y entender las visiones, proyectos y estrategias que adoptó el Estado borbónico con vistas a reestablecer la Marina Real; unos proyectos que no solamente se quedaron en la etapa de planificación, sino que también fueron puestos en marcha, como lo demuestran los contratos para el corte de madera. En el trabajo se aporta nueva información sobre los bosques y maderas americanas, con sus descripciones detalladas, además de la relativa a las inspecciones de montes realizadas por oficiales de la armada, cuya meta era la búsqueda de las mejores áreas madereras para la construcción de navíos. Finalmente, nos referiremos asimismo a la cuestión de los asientos novohispanos de la segunda mitad de la centuria, los cuales fueron monopolizados por las elites locales criollas.
\end{abstract}

Palabras clave: Siglo XVIII, Marina Real, Nueva España, recursos forestales, asientos, construcción naval.

Abstract. The objective of this article is a presentation of the theme about forest resources of the New Spain and their use for the development of the Spanish shipbuilding in the 18th century. The aspect little known by Spanish and Latin American historiography, however important to know visions, projects and strategies that took the Bourbon State in order to reestablish the Royal Navy. The contribution shows new information about American forests and woods with their detailed descriptions, as well as the inspections of forests made by Navy officers, who as their

Recibido: 6-3-2019 • Aceptado: 27-4-2019 • rafreich@yahoo.com 
goal had the research for the best wood areas. Finally, there is also mention a question of the New Spain asientos in the second half of the century that were monopolized by local creole elites. Keywords: 18th century, Royal Navy, New Spain, forest resources, asiento, Spanish shipbuilding.

EL SIGLO XVIII fue un periodo de desarrollo dinámico de la Marina Real. En cuanto a la fabricación de buques, su primera mitad puede considerarse como un momento de diseño y construcción de los fundamentos legislativos, administrativos y económicos, mientras que la segunda, se caracterizó por el desarrollo de la industria naval, el cual provocó a su vez el interés de las autoridades de la armada por la búsqueda de nuevas fuentes de recursos forestales para ella tanto en la Nueva España, como en otros lugares de Europa. Unas búsquedas que se realizaron con el fin de seleccionar las mejores maderas para la construcción de barcos de guerra en los astilleros peninsulares y en La Habana.

Uno de los impulsos a las inspecciones de bosques y selvas vino de la mano de la publicación de la Real Ordenanza de Montes de enero de 1748, que tuvo como finalidad proteger los intereses de la Marina y asegurarle un suministro continuo de maderas peninsulares. Sin embargo, esta obligación crearía un conflicto con las comunidades locales que tradicionalmente gozaban del derecho a utilizar los recursos forestales, pues sus intereses en este sentido se veían afectados por la citada ordenanza. Debido a ello, tras la destitución del Marqués de la Ensenada, en 1754, sería derogada, si bien sus consecuencias perdurarían durante varios años. Junto al deseo de evitar esta conflictividad, otro motivo para buscar nuevas áreas geográficas de donde extraer madera para la armada fue la progresiva deforestación que padecieron los bosques de Vizcaya, Cataluña y Aragón, pero, sobre todo, el deseo de las autoridades de garantizarse la reserva de los bosques peninsulares, los cuales podrían utilizarse como una fuente segura para el suministro de piezas de pino, roble y haya.

A día de hoy, la historiografía que trata los proyectos y prospecciones forestales llevados a cabo en las jurisdicciones del virreinato de la Nueva España es casi inexistente, hasta la fecha, que sepamos, no hay ninguna investigación en marcha sobre este tema. Por estos motivos, es muy importante centrar la atención en esta problemática para así comenzar a brindar resultados no solo a la historiografía naval, sino también a la forestal y ambiental. De hecho, en la región novohispana —en el territorio del México actual- únicamente contamos con la obra de Germán Andrade Muñoz (2006), Un mar de intereses. La producción de pertrechos navales en Nueva España, siglo XVIII, cuyo autor hace referencia en un apartado y de una manera general a los 
proyectos de prospección de bosques realizados en la provincia de Veracruz por el ingeniero de la Marina don Manuel de Corral, en los años de 1774 y 1778. Los demás trabajos relativos a los recursos forestales novohispanos y mexicanos se centran en la extracción de palo de tinte o de Campeche a fin de suministrar ese colorante a la industria textil. En este sentido, es importante mencionar los trabajos de Reinaldo Funes (2001 y 2004) y de Miguel Jordán Reyes (2006) sobre la deforestación en Cuba, los cuales contienen breves menciones a lo sucedido en los montes isleños, que fueron explotados para brindar suministros de cedro, caoba y otras especies madereras al astillero de La Habana; a pesar de ello, estas obras tampoco prestan atención a los proyectos de tala destinados a obtener piezas de madera para la armada. En cuanto al astillero cubano, conviene no olvidar los libros de José Manuel Serrano Álvarez (2008 y 2018): El astillero de La Habana y la construcción naval militar (1700-1750) y El astillero La Habana en siglo XVIII. Historia y construcción naval (1700-1805), cuyo autor presenta en ellos algunos ejemplos de proyectos sobre los suministros madereros, pero sin profundizar en el tema.

Es evidente pues la poca presencia en la historiografía de trabajos que traten directamente el aspecto de las materias primas forestales en Hispanoamérica con la intención de estudiar su suministro a la Marina Real. Sin embargo, gracias a las investigaciones que desarrolla el Contractor State Group / Red Imperial, dirigida por Rafael Torres Sánchez, esos últimos años se ha podido avanzar en el conocimiento de diferentes aspectos de las estrategias estatales sobre el aprovisionamiento de los astilleros y arsenales, no solo de las materias primas forestales sino también de las de otro origen, como cáñamos, velámenes o herrajes ${ }^{1}$. Al respecto, los trabajos de Iván Valdez Bubnov (2011), María Baudot Monroy (2012), Rafael Torres Sánchez (2013 y 2016), Manuel Díaz Ordoñez (2009, 2018) o Álvaro Aragón Ruano (2011 y 2017), estudian los desafíos que se decidió a enfrentar la corona a lo largo de la época moderna para conseguir esas materias primas, unas veces por sí misma y otras con la ayuda de gente de negocio proveniente tanto de la propia metrópoli como de las Indias y Europa. Los mencionados historiadores, al igual que los demás integrantes de este grupo de investigación, continúan sacando a la luz nuevos aspectos de la participación local, regional, estatal e internacional, en la movilización de recursos y materias primas para la monarquía, y cuyo objetivo final era el de mantener al Estado español en la competencia colonial.

Por lo expuesto, en el presente artículo pretendemos realizar un primer acercamiento al tema de los proyectos y las visiones que tenían los economistas y oficiales reales de la época sobre los recursos forestales y las maderas de la Nueva España, y

https://www.unav.edu/web/contractor-state-group 
averiguar si esos proyectos tuvieron alguna influencia en la estrategia sobre la que se asentaba el desarrollo de la Marina Real. Además de ello, pretendemos analizar los asientos de la madera novohispana ${ }^{2}$ gracias al manejo de una documentación que nos habla de los bosques de los actuales territorios de México y Cuba, y conocer quiénes fueron los individuos que estuvieron involucrados en los suministros de materias primas a los reales astilleros y arsenales. El trabajo terminará con un apartado donde se da cuenta del esfuerzo que realizaron los oficiales de la Marina al explorar los bosques de la Nueva España con el objetivo de establecer la utilidad de las diferentes especies de árboles, de definir cuáles eran las mejores áreas de tala y las rutas más adecuadas para el arrastre y la conducción de maderas tumbadas, tanto por tierra como a través de los ríos, hasta su destino.

La base de este estudio la conforman las instrucciones, inspecciones, proyectos, relaciones y asientos elaborados a lo largo del siglo XVIII por funcionarios reales y virreinales, oficiales de la Marina y comerciantes. Esta valiosa documentación se encuentra depositada en los fondos de Industria y Comercio y Correspondencia de Diversas Autoridades del Archivo General de la Nación de México. Cabe aclarar que una vez convenientemente explotadas estas fuentes, nuestro siguiente paso será la revisión y estudio de los fondos documentales conservados en los archivos españoles de Simancas y Viso del Marqués, para de este modo profundizar más aun en el conocimiento de los proyectos institucionales sobre los recursos forestales que desarrolló el Estado borbónico durante el siglo XVIII.

\section{Proyectos, visiones y posibilidades de extracción de madera de las Indias en la primera mitad del siglo XVIII}

La recuperación de la armada real fue un largo proceso que comenzó en el año 1714 con la creación de la Secretaría de la Marina. En ese momento, se sentaron las bases para su unificación y desarrollo. No obstante, la situación no fue fácil ya que en los primeros años del reinado de Felipe V, debido a la influencia del favorito del rey, Jean Orry, el proyecto de construir barcos en astilleros españoles propuesto por el primer secretario de la Marina, Bernardo Tinajero de la Escalera, se reorientó a la compra de los navíos necesarios en Francia (Inglis, 1985, p. 48). Con ello, se debilitaba la inicial pretensión real de desarrollar la construcción propia de barcos en la Península Ibérica y en las Indias. Aunque, lo cierto era que los cimientos ya estaban puestos, como

En el presente trabajo el término "novohispana/o" se usa para toda la extensión jurídica del virreinato de la Nueva España, la cual abarcaba los territorios actuales de México, de los países centroamericanos, de las Antillas Mayores y Venezuela. 
lo demuestran la creación de un sistema de construcción naval a la española diseñado por Antonio de Gaztañeta y el otorgamiento del primer asiento para construir navíos de línea con dicho estilo en La Habana ${ }^{3}$. Por esta razón, fue sólo cuestión de tiempo que arrancara, con toda su potencialidad, el desafío de crear una nueva y moderna armada real en España, lo que efectivamente sucedió en 1717, cuando José Patiño fue nombrado Intendente de la Marina, un oficial de gran energía, que comenzó a poner en práctica el plan de restablecimiento y fortalecimiento de dicha armada (Kuethe y Serrano, 2007, pp. 766-767).

Puede afirmarse entonces que las tres primeras décadas del siglo XVIII constituyen una fase experimental en el desarrollo de los proyectos dirigidos a evaluar y estimar las maderas que pudiesen extraerse de los bosques del Imperio español, así como de los orientados a sistematizar los suministros de madera para la construcción naval. En el caso de los bosques americanos, las primeras menciones a los recursos forestales destinados a la elaboración de buques se encuentran en la revolucionaria obra de catorce volúmenes Memoria sobre el gobierno de las Indias españolas, realizada por don Francisco de Seijas y Lobera para servir a la verdadera unión de las dos coronas de España y Francia (1702-1704), cuyo autor, el mencionado Francisco de Seijas y Lobera, estuvo en las Indias entre 1692 y 1701 . Durante ese tiempo trabajó en la Nueva España, en la Capitanía General de Guatemala y en el virreinato del Perú. Su experiencia con el aparato administrativo-burocrático de la gobernación indiana la plasmó en dicha Memoria, donde criticó el funcionamiento de los virreinatos en temas jurídicos, administrativos, económicos y militares. En su séptimo libro, titulado Gobierno militar y político del Reino imperial de la Nueva España, el autor hace varias alusiones al aprovechamiento de los recursos forestales del virreinato. Un ejemplo de ello lo tenemos en el siguiente fragmento:

y si para fabricar en ambos mares [del Sur y Norte] poderosas armadas se requiere en primer lugar las maderas, no hay países en todo el mundo más aptos para ellas que los de la Nueva España, porque como en los demás de aquellas Indias, se hallan en los puertos y costas de ambos mares las famosas y permanentes maderas de cedro y las de las caobas para hacer los cascos de los bajeles, y para arbolarlos los guayacanes, los pinos y otros árboles como son los cugues y marías (Seijas y Lobera, 1986, p. 293).

Con sus tratados de construcción naval Arte de fabricar Reales (1688) y Proporciones de las medidas arregladas a la construcción de un bajel de guerra de setenta codos de quilla (1712), revolucionó la elaboración de barcos de guerra en España. En el caso de Gaztañeta, es importante recordar que en 1702 fue nombrado superintendente de Fábricas y Plantíos de la Costa Cantábrica, cargo que le permitió gestionar astilleros y plantaciones de madera en Cantabria destinados a la Marina. En aquel entonces Gaztañeta organizó y centralizó la construcción naval española alrededor del astillero de Guarnizo. Por su parte, en 1713 la corona firmó un asiento con Manuel López Pintado para la construcción en La Habana de diez navíos de 60 cañones y dos de transporte durante cuatro años. 
Seijas y Lobera veía claramente que para defender las Indias y combatir el contrabando era necesario desarrollar una industria naval en los litorales, tanto del Pacífico como del Atlántico. Subrayaba, asimismo, que en el virreinato novohispano había una abundancia de diferentes especies de madera que servirían para construir buques.

\section{Mapa 1. Áreas boscosas inspeccionadas y de extracción de maderas con destino a la construcción naval durante la segunda mitad del siglo XVIII}

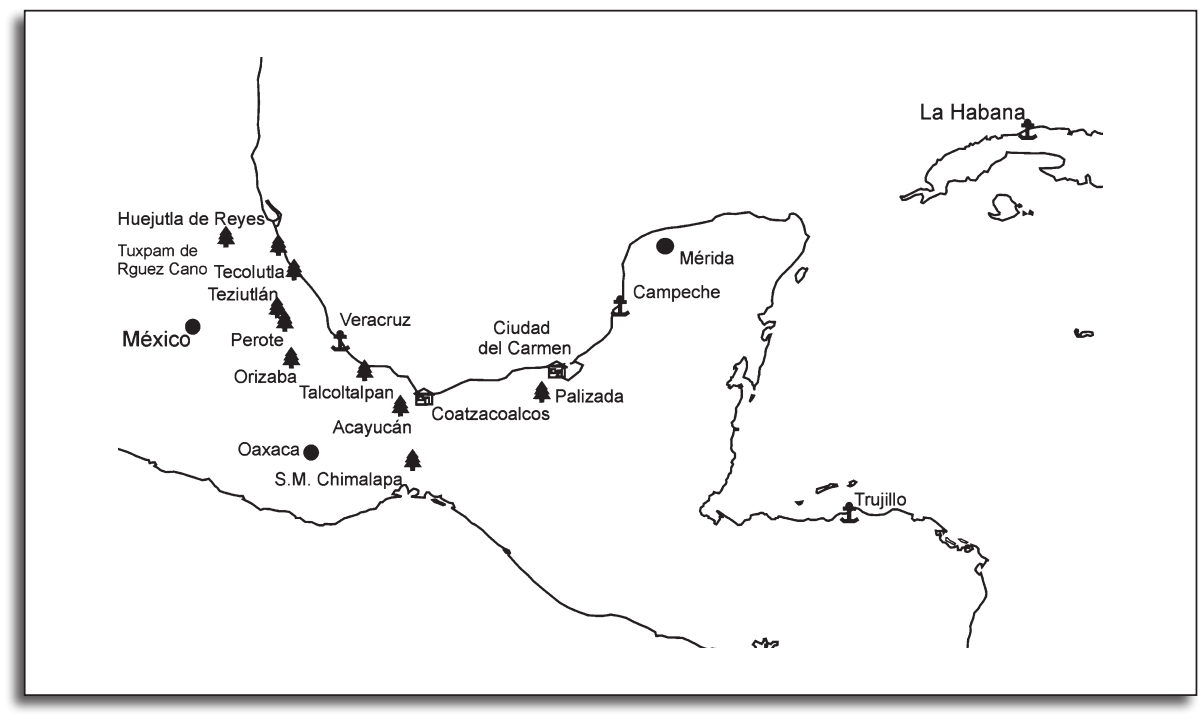

Por otra parte, es interesante mencionar que, a pesar de las presiones del lobby francés de Orry en la corte en los años 1701-1717, había en ella personas de la misma nación interesadas en apoyar el desarrollo de la armada real en España y Ultramar. Un buen ejemplo es el capitán Jean de Monségur, que fue consejero de Tinajero, si bien durante la Guerra de Sucesión Española (1701-1713), sería enviado por el gobierno francés a la Nueva España en misión de espionaje. Como resultado de este trabajo elaboró dos obras: Memoires du Mexique (1709) y Memoria que parece puede servir para formar una buena Armada en España (1712-1713), esta última entregada en mayo de 1713 al mencionado Tinajero. En ella, Monségur diseñaba un proyecto para restablecer la armada real enfocando su atención en la creación de una nueva estructura administrativa, diseñando sus funciones principales $\mathrm{y}$, por supuesto, una política de construcción naval (Valdez-Bubnov, 2009b, p. 86). Al igual que Tinajero y Patiño, estaba de acuerdo en desarrollar y fortalecer la fabricación de buques en América, sobre todo en el astillero de La Habana, con polos satélites en Pensacola, Veracruz, 
Tlacotalpan, Campeche y Maracaibo, puertos que formaban parte del virreinato novohispano. Desde estos lugares se garantizarían a La Habana los suministros de madera, brea y alquitrán, pero también se los consideraba ideales para la construcción de buques menores como fragatas, bergantines y goletas (Valdez-Bubnov, 2009a, pp. 67-90).

Años después, Jerónimo de Uztáriz, en su obra Teoría y práctica de Comercio y Marina (1724), concordaría con los planteamientos de Seijas y Lobera y de Monségur sobre el aprovechamiento de los abundantísimos bosques americanos para el uso de la Marina Real al mencionar que:

\begin{abstract}
son grandes también las ventajas que en las islas y tierra firme de la América tiene su majestad de muchas y exquisitas maderas y abundancia de brea y alquitrán para la construcción de bajeles particularmente en La Habana, Campeche y Cartagena de Indias. [...] con el considerable beneficio de que si los [navíos] fabricados en Europa duran de 12 a 15 años, [estos de América] se conservan más de 30, ya que se hacen allá con el cedro, roble más duro y otras maderas de superior firmeza y resistencia; lo que es causa también de que necesitan de menos carenas y de otros reparos. Fuera de que en un combate tiene también el cedro la ventaja de que embebe en si las balas, sin que se experimenten los efectos de los astillazos, que en los navíos fabricados en Europa, y que suelen maltratar y aun matar mucha gente. [...] Mucho convendrá al servicio de S.M. y al bien de sus barcos que todos los navíos que se hubiesen de emplear, así a la guardia de las Flotas y Galeones como en la Escuadra de Barlovento y otros mares de Indias, sean construidos de maderas de aquellas provincias [americanas] y en sus astilleros (Uztáriz, 1724, p. 216).
\end{abstract}

El economista español subraya en su obra la superioridad de las maderas indianas sobre las europeas, en particular, por su resistencia y por el tiempo que aguantaban en servicio. Además, menciona las propiedades particulares de los distintos tipos de madera, como es el caso de la de cedro, que no se deshace tanto como la de roble, por lo que no causará los comentados efectos del astillazo. Cabe decir que otros pensadores hispanos de la época de Felipe V, como Bernardo de Ulloa (1740, pp. 158 y 196), coincidían con los anteriores en el aprovechamiento de los buenos y abundantes recursos forestales de las Indias a beneficio del comercio español, pero también para el desarrollo de la Marina.

Así, el reinado de Felipe V puede considerarse como el periodo de creación de las estructuras legislativas, administrativas y económicas necesarias para el buen desarrollo de la Secretaría de la Marina. Durante ese tiempo, los ministros, intendentes y oficiales reales, al igual que los economistas y pensadores políticos, realizaron investigaciones sobre las necesidades de la corona en diferentes horizontes; el enfoque más claro de ellas era el que tocaba al restablecimiento comercial y a su defensa frente a los adversarios europeos, especialmente a la Gran Bretaña. En dichos infor- 
mes, memorias y relaciones aparece con frecuencia el tema de los recursos forestales, tanto peninsulares como americanos, que se podrían aprovechar para la construcción naval española. Varios de esos personajes de pensamiento progresista y renovador coincidían en que La Habana debería convertirse en el principal centro de la industria naviera de las Indias, en el núcleo estratégico que podría contar con un gran soporte de maderas provenientes de los bosques cubanos, pero también de los novohispanos, especialmente de los existentes en las provincias de Veracruz, Campeche y Florida.

\section{Inspecciones de montes y maderas novohispanas en la segunda mitad del siglo XVIII}

En el apartado anterior mencionamos las descripciones de Seijas y Lobera y de Jerónimo de Uztáriz sobre los bosques novohispanos, las cuales, apuntaban, serían de gran valor para la Marina y el comercio españoles. Sin embargo, ninguno de los dos era experto en materia forestal, por eso es importante contrastar sus opiniones con las de especialistas en carpintería y construcción naval. En la misma línea, decir que el interés científico por reconocer los montes novohispanos y definir los recursos que de ellos se podrían aprovechar para la fabricación de barcos apenas comenzó en la segunda mitad del siglo XVIII, cuando varios oficiales de la Marina realizaron detalladas inspecciones de bosques en Cuba y en el actual México. De hecho, la preocupación por encontrar las maderas más apropiadas para la industria naval estuvo presente entre las autoridades locales desde la década de 1760. Algo que también se comprueba en una orden de 1783, donde el ministro Antonio Valdés aclaraba al virrey novohispano que:

luego de que llegue el facultativo de La Habana deberá pasar al reconocimiento de los montes inmediatos al ribero de Alvarado y Coatzacoalcos, y demás parajes oportunos para el corte [de maderas], con vista de la dificultad de los acarreos, circunstancias territoriales y precio actual de las maderas habrá de extraer un pliego de condiciones, que comprenda todas las piezas útiles para construcción [naval] con sus calidades, dimensiones, y tamaños. Y añadió: las maderas que hasta ahora se conocen por más útiles para aquel fin, son cedro, caoba, jigüe, chicharrón o quiebra hacha, pero como puede haber en Nueva España algunas otras clases que también lo sean [útiles], se estará para su admisión al que diga el facultativo que se destine de La Habana ${ }^{4}$.

Las palabras del secretario de la Marina Valdés, explican claramente que para la extracción de madera buena y útil era necesario realizar reconocimientos no solo de

Archivo General de la Nación de México (en adelante AGNM), Industria y Comercio, vol. 10, exp. 11, fs. 248-249. 
los bosques, sino también de sus condiciones de arrastre por los montes y de transporte por los ríos. Además, encargó a los «facultativos», es decir, a oficiales de la Marina del departamento de La Habana, que no descuidasen la búsqueda de otras especies a fin de aprovecharlas en la construcción naval. Sin embargo, mucho antes de que Antonio Valdés fuese nombrado ministro de la Real Armada ya se habían realizado primeras exploraciones de las áreas boscosas novohispanas.

En el caso de Cuba, por ejemplo en enero de 1769, el comandante general del apostadero de La Habana, don Juan Antonio de la Colina, informó al virrey, el Marqués de Croix (1766-1771), de la llegada de los dos funcionarios reales - Francisco Mendoza, oficial de la Marina, y Joseph Chenar, ayudante de construcción - que iban a inspeccionar los montes de la isla y que vigilarían el corte de las maderas. Se les encargó que asegurasen 24.000 piezas labradas de todas clases para la construcción de navíos, desde 60 hasta 120 cañones. El comandante general comentó que todo estaba listo para cumplir con la real orden y que solo faltaba el dinero para la conducción de dichas maderas al astillero de La Habana. En una carta de mayo de ese mismo año, el virrey aseguraba que enviaría en la fragata Juno el mencionado dinero, para de este modo cumplir con el compromiso de transporte ${ }^{5}$. En el caso de Cuba, puede decirse que los funcionarios reales llegados de la metrópoli únicamente vigilaban la correcta selección de árboles para tumbarlos y labrarlos, a diferencia de lo que ocurría en los bosques novohispanos, donde todavía en la segunda mitad del siglo XVIII se conservaban áreas vírgenes no exploradas por carpinteros y cortadores. En este sentido, revisten especial interés las inspecciones asignadas en 1774 y 1778 al teniente-coronel de ingenieros de La Habana don Miguel del Corral, quien reconoció los ríos y montes de la provincia veracruzana, y la exploración que en 1777-1778 llevaron a cabo el alférez de fragata don Miguel Sapiain y el capataz de construcción Luis Fernández en la región de La Laguna de Términos. Fue este un gran avance en la valoración de nuevas regiones madereras, debido a que, y a diferencia de Cuba, donde ya estaban detectadas las zonas que contenían maderas útiles para su explotación y sólo había que poner atención a la correcta selección de los árboles, en la Nueva España faltaban todavía por explorar las mencionadas áreas vírgenes de bosques antes de poder siquiera proceder a la selección de las maderas para la construcción naval.

Al citado don Miguel del Corral, las autoridades del departamento naval de La Habana le encargaron en dos ocasiones el reconocimiento de los montes de la provincia de Veracruz. No eran estas las primeras misiones del oficial de la Marina, ya que desde su arribo a Veracruz en 1764 había explorado sus costas y el interior. En 1766 sabemos que formó parte de una expedición de reconocimiento del Golfo de México, y a partir

AGNM, Correspondencia de Diversas Autoridades, vol. 13, exp. 44, fs. 202-203. 
de ese momento comenzó a escribir sobre la geografía veracruzana. Primero realizó sus incursiones acompañado por el ingeniero militar don Agustín Crame, y después, por el capitán de fragata don Joaquín de Aranda, con quienes inspeccionaría los ríos que desaguan por las barras de Alvarado y Coatzacoalcos y los montes contiguos a ellos, hasta la provincia de Tehuantepec. También, se adentraría en la barra de San Francisco en la costa del Mar del Sur, y parte de la región de sotavento veracruzano (Moncada Maya, 2003).

Su primera expedición por los montes de Perote la realizó en el mes de mayo de 1774 en compañía de José Segurola, maestro mayor de carpintería de ribera de la maestranza de Veracruz. Ambos fueron enviados allí a petición de don Bernardo Nicolás de Lemos, administrador general de la Real Hacienda, quien sostenía que en Teziutlán y el Cofre de Perote había mejores pinos que los que se sacaban de Coatzacoalcos, además de subrayar que las arboladuras extraídas desde el interior hacia este último enclave eran muy costosas. El 20 de mayo de 1774, antes de regresar a Veracruz, don Miguel del Corral elaboró en San Miguel de Perote el Expediente sobre reconocimiento de maderas en los montes de Teziutlán y Perote para arboladuras de navios,${ }^{6}$ donde describía en detalle lomas, colinas, montes y ríos, con sus características respecto al tipo de piedra, peñascos y volumen, que uno podía encontrarse durante la época seca y la de lluvias.

en el sitio que llaman de Mecacalco, jurisdicción del pueblo de Atzalan, distante cinco leguas de este, doce de Jalapa, y diez de Perote, y treinta y cuatro de Veracruz, en la lengua de tierra que forman los ríos, de las Truchas y de Sosohuilco, hay abundancia de pinos de todos tamaños de buena calidad, la que sigue en la distancia de seis o siete leguas; pero solo hasta tres leguas pueden sacarse sin mucho costo, pues aunque el terreno como serranía tiene sus quiebras, hay cañadas y laderas por donde abrir el arrastradero, para que vaya a caer al río de Sosohuilco, en el paraje que llaman la Pila, donde se puede hacer un buen derrumbadero a poca costa, respecto a ser todo tierra este paraje, aunque muy pendiente, ya que dicho río que desemboca igualmente en la Barra de Nautla? .

En su informe describe otros sitios, como la loma de Tlalpopoca, donde encontró pino real, aunque no recomendó su tala debido al difícil acceso al mismo, que encarecía el costo total de las arboladuras. Describió que en el sitio llamado Atopa había buen pino; sin embargo, consideró que no era suficientemente abundante como para realizar cortes continuos por la cercanía a las ciudades de Xalapa y Coatepeque. En cambio, los potreros de Ygnes María y Chololoya ofrecían abundancia de pinos de todos los

AGNM, Industria y Comercio, vol. 10, exp. 5, fs. 101-111v.

AGNM, Industria y Comercio, vol. 10, exp. 5, fs. 102v. 
tamaños y muy limpios, además de hallarse cerca del río la Antigua (Mapa 1). Añadió que «a las faldas de la peña del Cofre hubo muchos parajes de pinos, pero más dificultosos de sacarlos y que hubo otras maderas útiles en abundancia, no distantes del río, como roble, encino y olmo». Concluye en su relación diciendo que «según parecer el costo de una arboladura completa de navío sacada al sur de la peña del Cofre, y legua y media distante de esta, y cinco de Perote, conducida por tierra con gente, cinco leguas hasta el río de Huixilapan, y a la Antigua ascendiera a 10.220 pesos de a ocho» ${ }^{8}$.

Comparando esta estimación con los precios que propuso don Domingo Ramos Balcarsel en su contrata de 1768, resulta que el cálculo de Del Corral superaba en el triple al que mencionaba este asentista novohispano, quien en su oferta a la administración daba los precios de tres o cuatro arboladuras completas. Al parecer, el informe de Del Corral no se utilizó con el fin de cortar arboladuras, visto que cuatro años después el teniente-coronel de ingenieros fue enviado nuevamente a verificar si existía o no la posibilidad de realizar tala de madera y su flotación hasta la barra de Nautla. En realidad, la expedición tenía por objeto encontrar palos de arboladura para los navíos de línea en los montes de Perote, y transportarlos a Veracruz y después a La Habana. De hecho, el comandante de dicho departamento, don Juan Bautista Bonet, solicitó «un estado de las perchas de pino y sus dimensiones que se pudiera cortar en las inmediaciones del Cofre de Perote, para el servicio de aquella escuadra, y por haberse reconocido anteriormente de ser esta madera de mucho mejor calidad que la que se ha conducido del río de Coatzacoalcos» ${ }^{9}$.

Del 12 al 20 de agosto de 1778, Miguel del Corral, Joseph Vicente Martínez, Cayetano José Rangel y cuatro monteros experimentados en el transporte de maderas de Coatzacoalcos realizaron un reconocimiento del río la Antigua. El 24 de agosto, el teniente-coronel de ingenieros terminó de elaborar la primera parte de su informe Sobre reconocimiento de los ríos de la Antigua y Nautla para conducir las arboladuras para buques del rey que pidió el señor comandante de la escuadra de La Habana, en el cual dictaminó con detalle el río, calificándolo como no apto para conducir las arboladuras de Perote al Golfo de México. En resumen, dice que:

el río se compone de vueltas en particular desde el rincón de Micela, para arriba son más obligadas y el río más precipitado; y él y sus orillas se componen de piedras de todas calidades, y en particular de lastre, los paredones son según reconocemos con las continuaciones de las lluvias y movimientos de terremotos, y el abatimiento del río no cesan de desgajarse y donde se debían los paredones de la orilla del río son unos bajos poblados de árboles y piedras que con creciente el río son de mucho perjuicio por sus grandes dimensiones ${ }^{10}$.

AGNM, Industria y Comercio, vol. 10, exp. 5, fs. 105.

AGNM, Industria y Comercio, vol. 10, exp. 10, f. 179-239v.

AGNM, Industria y Comercio, vol. 10, exp. 10, f. 209. 
Después, los comisionados inspeccionaron los pinos para arboladura en el sitio llamado Mecacalco, que en 1774 había reconocido el ingeniero Del Corral. Realizaron un corte de prueba de 18 palos de entre 30 y $45 \operatorname{codos}^{11}$, pero al iniciar el arrastre se dieron cuenta de que:

el arrastre de dicha madera, no le hallamos salida, por las muchas Barrancas imposibilitadas, por estar atravesadas las lomas de tierra, de un río a otro y ser a mucho repecho y desaguan estas barrancas arriba del paraje de la Pila, que es donde debía caer esta madera. También reconocemos, que este paraje no es terreno de maderas de pino pues los que se hallan, están muy salteados y los más tuertos y todos al pie hacheados por los Naturales, para reconocer si la hebra es apropósito para rajar tajamanil, y los más de estos se hallan por dichos hachados, huecos y nos hacemos cargo por lo visto, que los mejores habrán derribado pues hemos visto los troncones ${ }^{12}$.

Siguiendo el camino río abajo, la expedición se encontró con un claro de árboles caídos por los huracanes y otros derribados por «los Naturales» ${ }^{13}$, quienes los cortaban para las colmenas ${ }^{14} \mathrm{y}$ para rajar tajamanil ${ }^{15}$. Los expedicionarios observaron que los troncos hacía poco que habían sido tumbados ya que todavía tenían la corteza.

Entre los días 9 y 21 de septiembre de 1778, la expedición reconoció el río Santa María Tlapacoya que desemboca en el Golfo de México, en la barra de Nautla (Mapa 1). Los expedicionarios tampoco quedaron satisfechos con el resultado, y tras la inspección calificaron al mencionado río de inadecuado para el transporte de las arboladuras desde el Cofre de Perote. Al terminar la expedición, Joseph Vicente Martínez, Cayetano José Rangel y los cuatro monteros expresaron al administrador general de Veracruz, don Pedro Antonio y Cosío, su opinión sobre los pinos de esta zona: «que no eran muy diferentes a los que había en Coatzacoalcos». Por ello, se decidió buscar 34 palos en esta última ubicación, donde quizás fuesen de una calidad un poco menor, si bien se extraerían más fácilmente y el costo de ello no sería tan elevado como en el caso de hacerlo en el Cofre de Perote ${ }^{16}$.

Lo interesante de este informe es que, y comparándolo con el realizado en 1774, advierte del deterioro de los recursos forestales por las fuerzas naturales - huracanes,

11 En Castilla se utilizaba codo común que equivale a $0,418 \mathrm{~m}$; y codo real o de ribera que equivale a $0,574 \mathrm{~m}$. Desafortunadamente en los textos no se especifican cuales se utilizaban pero probablemente se refiere a los de ribera.

12 AGNM, Industria y Comercio, vol. 10, exp. 10, f. 209.

13 Se trata de indios que vivían en la región.

14 Panales de abejas.

15 Tablas delgadas que se utilizaban como las tejas en los techos.

16 AGNM, Industria y Comercio, vol. 10, exp. 10, fs. 234-235. 
vientos del Norte, derrumbes de piedras y tierra-, pero sobre todo por los indios, quienes aparentemente habían intensificado el corte ilegal de madera en la región del Cofre de Perote para elaborar con ella colmenas y tajamaniles.

Finalmente, en la correspondencia de don Juan Bautista Bonet aparece una propuesta más: la exploración de los montes que rodeaban el volcán de Orizaba, ya que en marzo de 1778 don Antonio de Ulloa había llevado a La Habana una muestra de los pinos de esa zona para los maestros mayores del arsenal, quienes, tras reconocerla detenidamente, dictaminaron que la madera era mucho mejor que la de Coatzacoalcos. El comandante del departamento cubano solicitó entonces que el coronel de ingenieros don Miguel del Corral hiciese otro informe, por el conocimiento que tenía sobre la región de Orizaba y sus cercanías, de la posibilidad de sacar esos palos del paraje donde se hallaban ${ }^{17}$.

Otro lugar visitado por los oficiales reales de la Marina fue la Laguna de Términos, que en aquel entonces estaba rodeada por densos bosques selváticos. Ese espacio acuático, con la isla de Términos o Tris a la entrada, era conocido desde la primera mitad del siglo XVI por la explotación de palo de tinte o Campeche, utilizado para teñir telas ${ }^{18}$. En el siglo XVII la isla fue invadida por cortadores de madera extranjeros, mayoritariamente ingleses. Los españoles recuperaron el control sobre la laguna tras una larga campaña militar de catorce años, el 16 de julio de 1717, cuando vencieron al último reducto de la defensa británica, fundando a continuación un presidio militar con fortificaciones y una guarnición permanente bajo la advocación de Nuestra Señora del Carmen, patrona de la Marina española (Rubio Mañé, 1984, pp. 301-304).

En relación con el tema que nos ocupa, es importante mencionar la gestión del gobernador del mencionado presidio del Carmen, don Pedro Dufau Maldonado, quien en abril de 1776 presentó un proyecto para utilizar el cedro y las maderas duras «de que abunda todo el recinto de aquella isla y las montañas que rodean toda la gran Laguna de Términos y noticioso del crecido valor que tienen en el día, las de esa isla para las obras del Rey para su industria naviera». De hecho la propuesta, además de referirse a los recursos forestales, mencionaba también el establecimiento de un astillero real para construir «fragatas u otros buques desde 24 hasta 30 cañones de fuerza». Dufau Maldonado, después de intercambiar varias cartas con el virrey, don Antonio María de Bucareli y Ursúa, y con el comandante de la escuadra de La Habana, don Juan Bautista Bonet, logró convencerles para que enviasen oficiales de la Marina con el objetivo de explorar la región y conocer su potencial maderero. Estos reconocimien-

AGNM, Industria y Comercio, vol. 10, exp. 10, f. 181.

"Tris" es otro nombre de la isla, el cual surgió de la abreviatura TRS, que se empleaba en la cartografía de la época colonial. 
tos fueron realizados desde noviembre de 1776 hasta enero de 1777 por el capataz de construcción Luis Fernández, quien se había dedicado durante muchos años al corte de madera como contratista, y por el alférez de fragata don Miguel Sapiain, quien auxiliaba a dicho carpintero. La evaluación de los recursos forestales fue positiva, con la recomendación de extraer árboles de cedro y de caoba, que luego serían enviados al arsenal de La Habana. Por otro lado, los comisionados desestimaban el establecimiento de un astillero real en la Laguna de Términos ${ }^{19}$.

Las gestiones del gobernador don Pedro Dufau Maldonado dieron fruto en la década de 1780, cuando las autoridades virreinales otorgaron varios permisos a comerciantes y oficiales reales del Carmen y Campeche para el corte de maderas duras y árboles de cedro a fin de suministrar a las atarazanas de Veracruz y del departamento de La Habana. Las cantidades enviadas no fueron significativas en comparación con las que se enviaba de la provincia veracruzana. Por lo regular, se solicitaban cantidades de alrededor de 500 codos cúbicos, como lo confirma una de las primeras talas realizadas por cuenta del gobernador del Carmen en 1781, cuando se gastaron 7.519 pesos y 2 reales en cortar los 400-500 codos de madera necesaria para el arsenal cubano ${ }^{20}$.

\section{Desarrollo de los asientos novohispanos en el siglo XVIII}

Se ha dicho que el reinado de Felipe $\mathrm{V}$ fue un periodo de diseño, centralización y consolidación de la Marina española. Durante ese tiempo se fortaleció la construcción naval peninsular en tres centros: Ferrol, en la cuenca cantábrica; Cádiz-La Carraca, en el litoral atlántico; y Cartagena, en el mar Mediterráneo. A partir de 1724, cuando José Patiño propuso el establecimiento de astilleros y arsenales reales, estos enclaves comenzaron a forjar su organización económica, administrativa y logística para garantizar la construcción de buques de guerra adecuados y para atender a sus mantenimientos. Dicha propuesta fue elaborada para romper el monopolio que ejercían las tradicionales regiones de construcción naval: el País Vasco, Cantabria y Cataluña. En este sentido, es incuestionable que a partir de proyecto centralizador diseñado por José Patiño comenzó un desarrollo ascendente de la industria naviera real, con altos y bajos, el cual perduró hasta el final de la centuria (Valdez-Bubnov, 2011, capítulo IV).

Quizás sea interesante saber que antes de la consolidación de 1724, en La Habana - ciudad que nota bene fue incluida en el plan de establecimiento de astilleros y arsenales reales - se había otorgado el primer asiento para la construcción de diferentes tipos de barcos con el objetivo de reforzar las fuerzas navales de la corona,

19 AGNM, Correspondencia de Diversas Autoridades, vol. 29, exp. 44, fs. 195, 200, 204-205v, 222-223.

20 AGNM, Correspondencia de Diversas Autoridades, vol. 34, exp. 30, fs. 114 y 118. 
al mencionado don Manuel López Pintado. No obstante, no sería hasta la llegada del capitán don Juan de Acosta a la maestranza del arsenal cubano, en 1722, que no se impulsó el proyecto de gran envergadura de recuperación de la armada real. Durante sus dieciocho años en servicio, este constructor participó en la fabricación de 23 embarcaciones en el astillero cubano (Kuethe y Serrano, 2007, pp. 768-769).

La Habana era un enclave idóneo para la industria naval del Estado borbónico, ya que contaba con una muy buena y fortificada bahía, además de abundantes bosques de cedro, caoba, sabicú y pino caribeño, colocados en el entorno del puerto y en la parte central de la isla (provincias de Sancti Spíritus y Camagüey). Las primeras menciones a su aprovechamiento para la construcción de barcos en el astillero de La Habana se remontan a finales del reinado de Felipe III, cuando el monarca expidió una real cédula en la que prohibía el corte de maderas en Cuba, «considerando que las maderas de caoba, roble y cedro, son de la mayor importancia para los navíos que se fabrican en la isla: Mandamos a los gobernadores y capitanes generales de ellas que no consientan ni permitan cortar ningunas, sino fueren para cosa de nuestro servicio o fábrica de navíos $\rangle^{21}$. En dicha orden se percibe el lugar privilegiado que se otorgaba a la construcción naval y el cuidado que debían tener las autoridades reales con las especies más necesitadas por la industria naviera.

Esta no sería la única orden, ya que durante la época de los Austrias también se sabía de la importancia de las maderas americanas para la construcción naval, en especial en La Habana, donde se estableció un cordón de protección para los bosques de la Armada que se encontraban cerca de la ciudad, a la vez que se limitó el corte de madera a una distancia de 10 leguas a sotavento y a barlovento de su puerto (Jordán Reyes, 2006, p. 52). Más aun, en los tiempos en que desarrollaban sus actividades de fabricación de embarcaciones López Pintado y Juan de Acosta, se dictó una real cédula para controlar el corte ilegal de maderas practicado por los dueños de ingenios azucareros, visto que estas eran necesarias para la construcción naval. Por esta razón, Felipe V resolvió:

que ninguno que no fuese fabricante de navíos pudiese hacer leña en términos en que hubiese ingenios sin acuerdo, y pagando a sus dueños lo que le concertase en ellos, y que estos cortes se hiciesen en la conformidad que previene la ley 7 , libro 7, título 7 de la Recopilación de Castilla para que los árboles no se corten por el pie sino por la rama, dejando tronco, horqueta y pendón: lo cual hiciese publicar por bando el Gobernador, haciendo justicia a los que la pidiesen contra los contraventores (Jordán Reyes, 2006, p. 53).

$21 \quad$ Recopilación de Leyes de Indias, libro IV, tema XVII, ley XIII. Don Felipe III en Madrid, 9 de julio de 1622. Consultado en Internet, http://fondosdigitales.us.es/fondos/libros/752/14/recopilacion-deleyes-de-los-reynos-de-las-indias/ [14 de enero de 2019]. 
Desde el mismo instante de su establecimiento en Cuba, la Marina Real tuvo constantes desacuerdos y debates con los dueños de los ingenios azucareros sobre el uso de las maderas, tanto de los montes reales como de los privados. Un conflicto que se prolongó hasta finales del siglo XVIII, cuando, con la caída de la industria naval de La Habana, los mencionados dueños de los ingenios se adueñaron de la mayor parte de los recursos forestales de la isla.

En relación con la extracción de madera en los bosques de la Nueva España, apreciamos que a lo largo del siglo XVIII se crearon cuatro centros de almacenamiento: Veracruz, Coatzacoalcos, el Presidio del Carmen y Campeche. En ellos, se reunían pinos, cedros, caobas y otras maderas duras taladas en los montes de la provincia de Veracruz y las selvas de Tabasco y la Laguna de Términos (Mapa 1). No se puede olvidar que la corona y los virreyes tenían el proyecto de crear un astillero real en Coatzacoalcos, para de este modo aprovechar las maderas de cedro y caoba de la región, pero también por la posición estratégica de este puerto, vista la buena comunicación que tenía con las regiones montañosas de Oaxaca y Veracruz, donde se extraía pino. La primera propuesta sobre la apertura de un astillero en este enclave se hizo en 1701 y la presentó el almirante de la Armada de Barlovento don Guillermo Morfi, aunque hasta 1718 la idea quedó en el papel. Dos virreyes darían un nuevo impulso al desarrollo de la industria naval en Coatzacoalcos, el marqués de Valero (1716-1722) y el marqués de Casa Fuerte (1722-1734). El primero no logró llevar a cabo su proyecto y el segundo, sí, al dar en 1726 José Patiño su visto bueno a la construcción de dos navíos de línea en el lugar. No obstante, desde el principio hubo problemas y desacuerdos tanto con los asentistas novohispanos como con los oficiales de La Habana, quienes no estaban a favor de enviar carpinteros a dicho recinto. El proyecto se redujo pues a la construcción de un solo navío, llamado San José, alias Nueva España, de 66 codos de quilla y 60 cañones de porte, cuya fabricación tuvo lugar entre 1731 y 1734, con un costo para Real Hacienda de más de 431.000 pesos de a ocho. Finalmente, las autoridades reales, a la vista de las enormes dificultades administrativas y logísticas, la corrupción y los altísimos costos, decidieron cancelar el proyecto de Coatzacoalcos y optar por seguir fabricando buques en La Habana (Andrade Muñoz, 2006, pp. 85-87).

A pesar de este fracaso, en la región veracruzana continuó la extracción de maderas duras y cedro para atender a las necesidades de los puertos cercanos (Tlacotalpan, Veracruz y Campeche) y de los departamentos navales ubicados en Cádiz-La Carraca, Ferrol, Cartagena y, en menor medida, de La Habana. La información más temprana que se ha identificado sobre asientos novohispanos destinados al suministro de madera a estos departamentos aparece en un contrato firmado entre la Real Hacienda y el capitán don Andrés Berdeja en 1742, por el cual este último se compromete a proveer 
a la Armada de Barlovento de piezas labradas de cedro y caoba (Andrade Muñoz, 2006, p. 88). Cabe decir que en las fuentes consultadas, además de este contrato, se encontraron y analizaron otros de la década de 1760. Así, por ejemplo, el siguiente asiento que aparece es del año 1766, y se otorgaba al brigadier general don Antonio Basilio Berdeja, apoderado de su padre el capitán don Andrés Berdeja. Lo interesante de este caso es que nos remite a la segunda generación de una misma familia, cuyo representante, el mencionado don Antonio Berdeja, recibiría aproximadamente 20 años después, un contrato por cinco años para entregar piezas labradas de caoba y cedro que se utilizarían en la fabricación de timones, cepos y cañas de timón, junto a tablas, tablones y ligazones, destinados a abastecer a los reales almacenes de Veracruz. Esta continuidad en la firma de contratos entre la familia de los Berdeja y la Real Caja veracruzana demuestra la importancia que tenía el negocio del asiento para las élites locales, así como su influencia en el ámbito administrativo del virreinato. Señalar que, en este caso, el corte de madera se efectuó en los montes de Tlacotalpan y que el valor del contrato se ajustó en 9.173 pesos de a ocho, de los cuales 4.000 se pagaron por adelantado. ${ }^{22}$ Por otro lado, sabemos que el virrey, el Marqués de Cruilles (1760-1766), no solo lo otorgó a beneficio de la Marina Real, sino que, además, lo consideró como una nueva fuente de ingresos para la Real Caja, ya que «un regular depósito de los palos y de piezas de cedro y caoba es necesario para las urgencias de los bajeles de la armada pero también para vender a los marchantes» ${ }^{23}$.

Es a partir de 1763, tras la derrota en la Guerra de los Siete Años (1756-1763), que en España se inicia un cambio importante en la organización administrativa de su imperio y una nueva dinámica de reformas militares y navales. Estas, fueron promovidas durante el reinado de Carlos III (1759-1788), y en ellas, la Marina Real se convirtió en un elemento clave de la política defensiva y ofensiva española. El esfuerzo de este monarca por desarrollar un proyecto imperial tuvo su reflejo en la importancia que llegaron a tener los suministros madereros de la Nueva España en el abastecimiento de los departamentos navales a partir de 1766. Así nos lo indica, por ejemplo, el mencionado contrato de los Berdeja o el corte de 510 palos de pino ordenado en 1767-1772 por la Real Hacienda en Santa María de Chimalapa, Oaxaca, para las arboladuras de los buques que se estaban construyendo en La Habana ${ }^{24}$. Al respecto, se realizaron varios de estos cortes en los bosques cercanos a la villa y las

AGNM, Industria y Comercio, vol. 10, exp. 2, fs. 50-63v.

AGNM, Correspondencia de Virreyes, serie 2, vol.11 exp. 102, f. 2.

En el año 1769, fue botado en La Habana el navío de línea más grande de la Marina, el Santísima Trinidad. Para montar su arboladura se utilizaron 60 pinos provenientes de los bosques novohispanos. Por ello se puede suponer que algunos palos de Santa María de Chimalapa se emplearon en su construcción. 
maderas se flotaron hasta Coatzacoalcos, donde fueron cargadas en barcos. Desde el principio el gran problema fue la falta de embarcaciones suficientes para transportar los palos a Cuba. Por ejemplo, en junio de 1769 se transportaron apenas 54 piezas en dos paquebotes de Su Majestad, el San Lorenzo, que cargó 27 pinos en ocho días, y el San Francisco de Paula, que cargó 37 palos en diez. Aunque, como menciona en su oficio Joseph Jiménez, encargado del segundo corte de maderas, «por ser lastima cortar los palos largos que hay, se quedan en Tlacotalpan 43 pinos al cargo de vigía de Juan Ángel Jáuregui» ${ }^{25}$.

Si la falta de barcos para el transporte de las maderas fue un obstáculo, el corte de esos palos también, al igual que la suspensión de las labores forestales por falta de pago, el robo de herramientas y víveres, la pérdida de piezas en las peñas del río y las flotaciones canceladas debido al bajo nivel del agua de los ríos. Igualmente, cabe mencionar el intento de establecer otro asiento de arboladuras de pino provenientes de la región veracruzana en 1768, el cual fue asignado a don Domingo Ramos Balcarsel. Este contratista se comprometió a realizar el corte de tres arboladuras completas para navíos de ochenta cañones por un costo de 12.000 pesos de a ocho; tres más para navíos de setenta cañones por 11.000 pesos de a ocho; cuatro arboladuras de sesenta cañones por 10.000 pesos de a ocho; y seis para fragatas de treinta cañones por 5.500 pesos de a ocho. Con el fin de hacer su oferta más atractiva para la Real Hacienda, el asentista ofreció un descuento del 8\% sobre el precio total, lo cual fue autorizado, primero, por el virrey, el Marqués de Croix, y después, el 25 de julio de 1768, por el mismo rey. La orden real fue enviada a la Nueva España junto con una lista elaborada en el astillero de La Carraca, en la que figuraban el número y las dimensiones de los palos. Sin embargo, por alguna razón desconocida, el contrato no se concretó, si bien el presupuesto que figuraba en él sirvió para realizar luego comparaciones con otros que se asignaron posteriormente ${ }^{26}$.

No se conserva mucha información sobre los asientos novohispanos para la década de 1770. Aparecen, eso sí, algunas menciones, como el que se firmó en Cuba en 1771 para la provisión de maderas entre el intendente de la Marina en La Habana, el Conde de Macurijes, y don Francisco Franchi Alfaro, el cual llevaba los dictámenes de los generales don Andrés Eeggío, don Manuel de Flores y don Pedro Castejón para la fabricación de navíos según el sistema de Gautier (Fernández Duro, 1895-1903, t. 7, p. 418). Cabe aclarar que, después de la época de Acosta (décadas de 1720 y 1730), el asiento para abastecer de maderas al astillero habanero y construir barcos fue transferido a la Real Compañía de La Habana mediante un contrato por 10 años

AGNM, Industria y Comercio, vol. 10, exp. 1, fs. 1-49.

AGNM, Industria y Comercio, vol. 10, exp. 5, fs. 100-111v. 
realizado entre 1740 y 1751, que sería el más costoso del siglo. Por esta razón, de 1764 a 1790 la responsabilidad del suministro de madera quedaría en manos de la comandancia de la Marina.

En esta última etapa de desarrollo de los asientos cubanos es interesante la propuesta efectuada en 1777 por el contador de navío don Manuel Carlos Garibaldo, en su papel de responsable del planeamiento, gestión de los recursos económicos y adquisición de efectos, quien escribió una Instrucción [...] para plantificar y establecer dos cortes de madera dura y de cedro con sus respectivos requisitos para construcción de dos navios de 60 cañones $^{27}$. Esta Instrucción sería enviada en octubre de 1777 al virrey, don Antonio María de Bucareli y Ursúa. En ella, Garibaldo demuestra la capacidad e interés de los oficiales de la Marina en diseñar un sistema adecuado y eficaz de suministros madereros al objeto de cubrir las necesidades del astillero de La Habana. El texto puede considerarse como un manual formado por 42 puntos, que aparecen divididos en tres partes donde el autor especifica: $1^{\circ}$ ) las necesidades de clavazón, herramientas, utensilios, animales de carga y despensa para el capellán y el cirujano, además de cómo poner en pie la capilla y las chozas organizadas en dos ranchos de cortadores; $2^{\circ}$ ) los recursos humanos necesarios con sus sueldos, incluyendo en ellos el uso de presidiarios como mano de obra; $3^{\circ}$ ) las medidas y cantidades exactas de maderas duras y de cedro para la construcción de dos navíos.

En lo referido a dichas maderas, se percibe el conocimiento práctico de Garibaldo en el tratamiento de esta materia prima, por ejemplo, proponía que los cortes se realizaran a lo largo de 12 o 13 meses - tumba, labor y tiro- para detener la tala entre noviembre y febrero de cada año a fin de que «no se experimentase jugosidad competente de dichos arboles [de cedro] para el logro de su sanidad y precaución de toda posterior podrición». Asimismo, estimaba que para construir esos dos navíos de 60 cañones sería necesario labrar 3.877 piezas de construcción y 2.080 tozas para la tablonería de fondo, forros y obras muertas de cedro. Proponía por ello, cortar a mayores un tercio más de la madera solicitada para que emplearla como soporte para la construcción y suplir las piezas dañadas. El total de madera de cedro a emplear la calculó en unos 7.939 árboles, con un promedio de 462 cedros tumbados por mes. En cambio, en relación a las maderas duras (caoba, sabicú y yaba), contabilizó 1.048 piezas labradas, cuyo número, ante los posibles daños a los árboles, aumentó en un sexto. Estableció entonces el volumen de corte en 1.223 árboles, a conseguir gracias a una media de 88 piezas taladas por mes. La región donde proyectaba conseguir la

AGNM, Indiferente virreinal, Marina, caja 4737, exp. 46, fs 1-65. El nombre completo del documento es: Instrucción hecha por el contador de navio de la Real Armada, don Manuel Carlos Garibaldo para plantificar y establecer dos cortes de madera dura y de cedro con sus respectivos requisitos para construcción de dos navios de 60 cañones. 
madera era la de Yaguajay. Sin embargo, la Instrucción no despertó el interés del virrey, el mencionado don Antonio María de Bucareli y Ursúa, quien medio año después de recibirla, el 26 de abril de 1778, comunicaba a Garibaldo: «aún no he podido ver este documento» ${ }^{28}$. Éste, tiene un gran valor histórico por la minuciosa información que proporciona, gracias a la cual es posible hacerse una idea de los recursos humanos y económicos, las herramientas, animales y otros pertrechos que se necesitaban para poner a punto un corte de madera destinada a la construcción de navíos de línea en La Habana. Además, la Instrucción tiene un enorme valor para la historia social, en particular, por la información que contiene acerca de la buena organización de la vida en los ranchos de cortadores, o de los cuidados que se esperaban dar a las almas y buena conducta de soldados, carpinteros, capataces y presidiaros, quienes:

a efecto que no les falte el pasto espiritual estando las cortas distantes de poblado dos leguas será también preciso nombrar un capellán que con el gozo de 30 pesos al mes y dos raciones diarias, diga misa las días de fiesta y festivos; y en tiempo de cuaresma les explique la doctrina cristiana y confiese a cuyo importante objeto se hará un cuartico de tablas, pintado y curioso que sirva de capilla y comprará por cuenta de la real hacienda la caja de ornamentos necesarios y adorno decente para dicha capilla que todo no llegará a 1.000 pesos $^{29}$.

Volviendo a los asientos novohispanos, hay que decir que su dinámica cobró un nuevo impulso en 1783, cuando el ministro de la Marina don Antonio Valdés (1783-1795), expidió al virrey, don Matías de Gálvez y Gallardo (1783-1784), una orden por la que se autorizaban los cortes de maderas duras y de cedro para el suministro de los departamentos navales de Cádiz-La Carraca, Ferrol, Cartagena y La Habana $^{30}$. En correspondencia con ello, al año siguiente se concedieron cuatro asientos a individuos que formaban parte de las élites de la provincia de Veracruz: uno, a don José Jiménez, capitán de milicias de Tuxpan, quien acordó con la administración la entrega de 10.000 codos cúbicos de piezas de «todas clases de madera» fuerte y de cedro; otro, a don Esteban Bejarano, vecino de la ciudad de Veracruz, que recibió un contrato para proveerla de 2.000 codos cúbicos de las mismas piezas y 50 curvas de todas clases; el tercero, se dio a don Pedro Moscoso, vecino de Acayucan, quien aceptó la remisión de 4.000 codos cúbicos de piezas de «todas clases de madera» de cedro; y el cuarto, a don Ramón Carvallo, vecino de Tlacotalpan, quien se comprometió a entregar 4.000 codos cúbicos de piezas.

AGNM, Indiferente virreinal, Marina, caja 4737, exp. 46, fs. 2v-6v.

AGNM, Indiferente virreinal, Marina, caja 4737, exp. 46, f. 13.

AGNM, Industria y Comercio, vol. 31, exp. 8, f. 170. 
En todos estos contratos figuraba el término «todas clases de madera», lo que significa que en los asientos se solicitaba todo tipo de piezas, «desde quillas hasta cepos de anclas con arreglo al plan formado por el delineador de construcción, Luis del Toral, con arreglos a sus dimensiones señaladas y en los reglamentos que se les entregaron $»^{31}$. Dos años después, en 1785, se renovaron los contratos de Carvallo, Moscoso y Bejarano, solicitándoseles esta vez la entrega total de 7.500 codos cúbicos de madera más otras piezas labradas. En 1786 se otorgó un nuevo asiento a don Francisco Sánchez de Burgos, subdelegado de la Antigua, quien se comprometió a entregar de 3.000 a 4.000 codos cúbicos de las más variadas piezas de cedro (Reichert, 2019). Sin embargo, con las dificultades derivadas del acopio de maderas y su transporte a los departamentos navales, la falta de embarcaciones de Su Majestad y la escasez de recursos económicos de la Real Caja, los contratos firmados apenas un año antes fueron renegociados y, finalmente, cancelados a inicios de 1787. De las piezas reunidas, muchas se descompusieron debido a que se habían almacenado en la playa Mocambo, cerca de Veracruz, donde quedaron expuestas al agua y al sol.

Del análisis de los asientos novohispanos de la década de 1780, cabe concluir que esta fue una época de bonanza para la élite criolla veracruzana, cuya posición económica y poder local contribuiría a partir de entonces a obstaculizar el acceso a los contratos de los peninsulares. El ejemplo más claro es el de la casa Uztáriz, asociada con los Cinco Gremios Mayores, la cual, el 17 de enero de 1784, a cambio de adquirir de la Marina el navío San Leandro, se comprometió a entregar al arsenal de La Carraca 8.000 codos cúbicos de cedro provenientes de la Nueva España ${ }^{32}$. El 7 de junio de ese año, el virrey don Matías de Gálvez y Gallardo expidió una orden para que se facilitara y diera acceso a las maderas de Acayucan a la casa comercial representada por don Juan Felipe Uztáriz. Este nombró como representante de sus interés a un comerciante de Veracruz, don Remigio Fernández, quien encargó cortar y almacenar dichas maderas a Pedro Moscoso, también asentista de maderas por el contrato firmado con la Real Hacienda en abril de 1784, por el cual se comprometía a entregar 4.000 codos cúbicos de piezas de todas clases de cedro a 4 pesos y 2 reales cada pieza. El conflicto de intereses, no tan solo de los suyos, sino también de los otros asentistas de la región — don Esteban Bejarano, y don Ramón Carvallo-, hizo que a lo largo de 1784 y 1785 no fuese posible cortar ni un solo árbol, debido, principalmente, a que, primero, no pudo encontrarse un área adecuada para realizar la tala, luego, por la falta de mano de obra y, finalmente, por los problemas en la organización del transporte. Durante esos dos años el virrey dio todo su apoyo a la casa

AGNM, Industria y Comercio, vol. 31, exp. 5, f. 104v.

AGNM, Reales Cédulas Originales, vol. 135, exp. 104, fs. 221-221v. 
Uztáriz. Sin embargo, las solicitudes de ésta caían en el vacío en el momento de ser transferidas a los comerciantes locales de la provincia de Veracruz. Por esta razón, el 5 de noviembre de 1786 se canceló el asiento, pues «dicho Uztáriz ha quebrado, y cesado con este motivo la contrata, ha resuelto S.M. que cesen los referidos cortes de madera y que para ello de V.E. las providencias más oportunas». El expediente se cerró el 9 de mayo de 1787, cuando los oficiales de Veracruz recibieron la última instrucción sobre la cancelación del mencionado desafío ${ }^{33}$.

\section{Reflexiones finales}

El siglo XVIII se inició con un cambio dinástico en el trono de España, lo que a su vez abrió el paso a nuevos proyectos y visiones sobre la reforma y mejoramiento de la administración, la economía, el comercio, el ejército y la armada. En el caso de esta última, es incuestionable la intensa gestión que realizaron marinos ilustres para devolver a la Marina Real su prestigiosa posición y la operatividad bélica necesaria para enfrentarse a los poderes navales de Europa. Por este motivo, cabe considerar a la primera mitad del siglo como un período de diseño, creación y construcción de los fundamentos legislativos, administrativos y logísticos — con la enorme contribución de Patiño, Marqués de La Victoria, Marqués de La Ensenada y otros - para el desarrollo de la construcción naval, con la planificación de los distintos tipos de embarcaciones diseñados por Gaztañeta y Jorge Juan.

La segunda mitad del siglo XVIII se puede definir, en cambio, como una fase de constante crecimiento del poderío naval español, sobre todo durante el reinado de Carlos III, monarca que, después de la derrota española en la Guerra de los Siete Años, se dio cuenta de que solo una armada moderna podría enfrentarse a la hegemonía de la Gran Bretaña. Durante su gobierno, los oficiales de la Marina demostraron un constante interés por acceder a nuevas fuentes de recursos forestales, tanto en la metrópoli y Europa como en América, al objeto de desarrollar un sistema de suministros capaz de cumplir con las demandas de los astilleros reales en Ferrol, Cádiz-La Carraca, Cartagena y La Habana. En este sentido, los ministros de la Marina pusieron sus miradas en diferentes regiones geográficas, en aquellas desde las que pudieran recibir las maderas para la construcción y el mantenimiento de los buques. En caso de las Indias, lo confirman los proyectos de reconocimiento de bosques abundantes en pino, cedro, caoba, sabicú y guayacán. Las expediciones a los montes novohispanos realizados por los oficiales de la corona, como fue el caso de don Miguel del Corral, expresan la necesidad de asegurar el suministro de materias primas a los

AGNM, Industria y Comercio, vol. 10, exp. 12, fs. 379-401v. 
arsenales. Y aunque en el presente artículo únicamente se ha estudiado lo sucedido a las maderas mexicanas, los diferentes proyectos propuestos por las autoridades y comerciantes locales demuestran que también se buscaba extraer cedro en el ámbito del Gran Caribe de la región de Cumaná de la Capitanía General de Venezuela y del virreinato de Nueva Granada. Unos territorios que todavía no han recibido la conveniente atención de los historiadores, por lo que es poco o nada lo que sabemos acerca del uso de sus maderas en las diferentes estrategias navales diseñadas por la Marina en el curso del siglo XVIII.

La búsqueda de recursos madereros en Hispanoamérica tuvo lugar en buena medida gracias a la necesidad de emplear diferentes tipos de maderas para fortalecer el casco de los barcos, visto, por ejemplo, que las quillas y sobrequillas de caoba eran más duraderas que las de roble. También gracias al acceso directo del Estado español a sus recursos ultramarinos, lo que le permitía mantener un mayor control sobre los contratos, la extracción de madera y su transporte a manos de criollos y españoles, demostrando así la existencia y práctica por parte de la corona de estrategias mercantilistas con el objetivo de defender sus intereses económicos. Curiosamente, en el caso novohispano, esto permitió que la elite criolla local creciese, se afianzase y ganase un poder económico y político suficiente como para monopolizar los asientos de maderas para la Armada Real en la segunda mitad del siglo XVIII. Algo que se debió, en parte, a sus buenas relaciones con los oficiales reales, quienes les concedían contratos para cortar y elaborar piezas de madera. De este modo, los novohispanos fueron capaces de obstaculizar la entrada en el negocio de los comerciantes de origen peninsular, tal y como por ejemplo lo demuestra lo sucedido con la Casa de Uztáriz, la cual se enfrentó a la fuerte oposición de los asentistas veracruzanos, quienes sin darles su apoyo la obligaron renunciar su contrata de madera en montes de Veracruz.

Las estrategias y los proyectos que puso en marcha la Marina, como la gente relacionada con ella, demuestran la gran capacidad de los particulares para hacer negocios atendiendo a la finalidad de levantar y mantener el poderío naval español. La participación de la administración central y local, y del sector privado procedente de España, América y Europa, confirma la contribución del Estado borbónico a la globalización temprana, ya que contribuyó mediante los contratos que fue otorgando a poner en relación negocios de diferentes regiones del mundo atlántico, mientras que el producto que lo logró fue la madera. 


\section{AGRADECIMIENTOS}

El presente artículo es producto del Proyecto: The role of wood supplies from the southern Baltic region and the viceroyalty of New Spain in the development of Spanish seaborne empire in the eighteenth century, financiado por The National Science Center, Poland, Referencia: 2017/25/B/HS3/01017. 


\section{Bibliografía}

ANDRADE MuÑoz, Germán (2006), Un mar de intereses. La producción de pertrechos navales en Nueva España, siglo XVIII, México, Instituto Mora.

ARAGÓN RUANO, Álvaro (2011), «La historiografía forestal sobre época moderna en el panorama internacional, español y vasco: una revisión bibliográfica», Vasconia, 37, pp. 117-140.

Aragón Ruano, Álvaro (2017), «Mar de árboles, vorágine de jurisdicciones. La complicada relación entre la Real Armada española y los bosques del Pirineo Occidental peninsular en el siglo XVIII», en Varela Gomes, Rosa y Trapaga Monchet, Koldo (eds.), Árbores, barcos e homens na Península Ibérica (séculos XVI-XVIII), Lisboa, Instituto de Arqueologia e Paleociências da Universidade Nova de Lisboa, pp. 41-53.

Baudot Monroy, María (2012), «Barcos para el rey. Julián de Arriaga, la madera y la construcción naval, (1752-1754)», en García Hurtado, Manuel-Reyes (ed.), La Armada española en el siglo XVIII. Ciencia, hombres y barcos, Madrid, Silex, pp. 297-328.

DíAz OrdoñEz, Manuel (2009), Amarrados al Negocio. Reformismo borbónico y suministro de jarcia para la Armada Real (1675-1751), Madrid, Ministerio de Defensa.

DíAz OrdoÑEz, Manuel (2018), «Radiografía de un fracaso angloespañol: el cáñamo, un producto que debería de haber llegado de América durante los siglos XVIXIX», Obradoiro de Historia Moderna, 27, 2018, pp. 263-289. https://doi. org/10.15304/ohm.27.5138

FERnÁndez Duro, Cesáreo (1895-1903), Armada española desde la unión de los reinos de Castilla y de León, Madrid, Sucesores de Rivadeneyra, t. 7.

FUNES, Reinaldo (2001), «Azúcar y deforestación. Una aproximación a la historia ambiental en Cuba» en González de Molina, Manuel y Martínez Alier, Joan (eds.), Naturaleza transformada. Estudios de historia ambiental en España, Barcelona, Icaria, pp. 183-209.

FunEs, Reinaldo (2004), De bosque a sabana. Azúcar, deforestación y medio ambiente en Cuba: 1492-1926, México, Siglo XXI.

IngLIS, Douglas (1985), «The Spanish Naval Shipyard at Havana in the Eighteenth Century», Selected Papers from the 5th Naval History Symposium New Aspects of Naval History, Baltimore, The Nautical Aviation and Publishing Company of America, Baltimore, United States Naval Academy, pp. 47-58.

JoRdÁn ReYes, Miguel (2006), «La deforestación de la Isla de Cuba durante la dominación española: (1492-1898)», Madrid, Universidad Politécnico de Madrid [Tesis doctoral inédita]. 
Kuethe, Allan y Serrano Álvarez, José Manuel (2007), «El astillero de La Habana y Trafalgar», Revista de Indias, vol. 67, 241, pp. 763-776. https://doi.org/10.3989/ revindias.2007.i241

Moncada MaYa, Omar, (2003), «Las defensas de Veracruz en 1783, según una relación del ingeniero Miguel del Corral», Biblio 3W. Revista Bibliográfica de Geografía y Ciencias Sociales, de Barcelona, vol. 8, 456. Consultado el 27 de enero de 2019: http://www.ub.edu/geocrit/b3w-456.htm

Recopilación de Leyes de Indias, libro IV, tema XVII, ley XIII. Don Felipe III en Madrid, 9 de julio de 1622. Consulta del 14 de enero de 2019: http://fondosdigitales.us.es/ fondos/libros/752/14/recopilacion-de-leyes-de-los-reynos-de-las-indias/

REICHERT, Rafal (2019), «¿Cómo España trató de recuperar su poderío naval? Un acercamiento a las estrategias de la Marina Naval sobre los suministros de materias primas forestales provenientes del Báltico y Nueva España (1754-1795)», Revista Espacio, Tiempo y Forma, Serie IV de Historia Moderna, 32, pp. 73-102. https://doi.org/10.5944/etfiv.32.2019.22242

Rubio MaÑÉ, José Ignacio (1983), El virreinato vol. III. Expansión y defensa, México, FCE/UNAM.

SeiJAs y LoberA, Francisco (1702-1704), Memoria sobre el gobierno de las Indias españolas, realizada por don Francisco de Seijas y Lobera para servir a la verdadera unión de las dos coronas de España y Francia [Archivo del Ministerio de Asuntos Exteriores de Francia, Mem, et Doc. (Esp.), 130].

SEIJAS y Lobera, Francisco (1702), Gobierno militar y político del Reino imperial de la Nueva España, México, UNAM [edición de 1986].

SERrano Álvarez, José Manuel (2008), El astillero de La Habana y la construcción naval militar (1700-1750), Madrid, Ministerio de Defensa.

SERrano Álvarez, José Manuel (2018), El astillero La Habana en siglo XVIII. Historia y construcción naval (1700-1805), Madrid, Ministerio de Defensa.

Torres SÁnchez, Rafael (2013), El precio de la guerra. El estado fiscal-militar de Carlos III, Madrid, Marcial Pons.

TORRES SÁnchez, Rafael (2016), Military Entrepreneurs and the Spanish Contractor State in the Eighteenth Century, Oxford, Oxford University Press.

UlloA, Bernardo de (1740), Restablecimiento de las fábricas y comercio español: errores que se padecen en las causas de su decadencia, y los medios eficaces de que florezca, Madrid, Antonio Marín.

UzTÁRIz, Jerónimo de (1724), Teoría y práctica de Comercio y Marina, Madrid, Antonio Sanz. 
VALDEZ-Bubnov, Iván (2009a), «De Monségur a Uztáriz: el origen de las reformas navales de Felipe V, 1712-1726» en Martínez López-Cano, María del Pilar (ed.), Historia del pensamiento económico: testimonios, proyectos y polémicas, México, UNAM-Instituto Mora, pp. 67-90.

VALDEZ-Bubnov, Iván (2009b), «War, Trade and Technology: The Politics of Spanish Shipbuilding Legislation, 1607-1728», International Journal of Maritime History, vol. 21, 2, pp. 75-102. https://doi.org/10.1177/084387140902100205.

Valdez-Bubnov, Iván (2011), Poder naval y modernización del Estado. Política de construcción naval española (siglos XVI-XVIII), México, Universidad Nacional Autónoma de México. 
